\title{
North American urogynecology fellowship programs: value of program website content
}

\author{
Mehr Jain ${ }^{1}$ (D) Nilita Sood $^{2} \cdot$ Rhea Varguise $^{3} \cdot$ Dalia Limor Karol $^{4} \cdot$ Ahmad B. Alwazzan $^{5} \cdot$ Faisal Khosa $^{3}$
}

Received: 17 February 2021 / Accepted: 17 April 2021 / Published online: 28 April 2021

(C) The International Urogynecological Association 2021

\begin{abstract}
Introduction and hypothesis Urogynecology fellowship program websites are an important source of information to potential applicants, especially given the ongoing COVID-19 pandemic and resulting travel restrictions. Our study evaluated the publicly available information on American and Canadian urogynecology fellowship websites and present recommendations for website content development to promote the subspecialty of urogynecology.

Methods Data were collected from all active American and Canadian urogynecology fellowship program websites between May and June 2020 against 72 criteria developed from previously published studies. The criteria included the following sections: Recruitment, Faculty Information, Current Fellows, Research and Education, Surgical Program, Clinical Work, Benefits and Career Planning, Wellness, and Environment.

Results 54 American urogynecology program websites and 11 Canadian urogynecology program websites were analyzed. The mean score of American and Canadian websites was $46.46 \%(n=33.45 \pm 7.20$ out of 72$)$ and $27.40 \%(n=19.73 \pm 3.77$ out of 72 ), respectively. American program websites scored significantly higher on available information than Canadian websites. The highest prevalence section across American websites was Wellness (64\%, $n=1.92 \pm 0.85$ out of 3 criteria) while the lowest prevalence section was Clinical Work $(15.17 \%, n=0.91 \pm 1.02$ out of 6 criteria). Comparatively, Canadian websites scored highest in the Faculty Information section $(43.12 \%, 3.45 \pm 2.02)$ and lowest in the Clinical Work section $(6 \%, n=0.36 \pm 0.67$ out of 6 criteria).

Conclusions American and Canadian websites thoroughly covered the Wellness and Faculty Information sections, respectively. Program websites should consider adding details about Benefits and Career Planning and Clinical Work.
\end{abstract}

Keywords Urogynecology $\cdot$ Urology $\cdot$ Fellowship $\cdot$ Program website $\cdot$ Obstetrics and gynecology

\section{Introduction}

Information on websites for residency and fellowship programs affects an applicant's choice and opinion of the program.

Mehr Jain

mjain030@uottawa.ca

1 Faculty of Medicine, University of Ottawa, Ottawa, Ontario, Canada

2 Faculty of Medicine, Memorial University of Newfoundland, St. John's, Newfoundland, Canada

3 Department of Radiology, Vancouver General Hospital, Vancouver, British Columbia, Canada

4 Department of Obstetrics and Gynecology, University of Toronto, Toronto, Ontario, Canada

5 Department of Obstetrics and Gynecology, Faculty of Medicine, King Abdulaziz University, Jeddah, Saudi Arabia
Specifically, fellowship applicants often look to program websites as their main source of information when choosing a fellowship program far from where they are originally from or intend to practice [1]. Due to the current COVID-19-related travel restrictions, many residency and fellowship applicants cannot visit the programs for site visits or interviews during the application process. Online communication and resources, such as program websites, are now some of the few sources of information which applicants can use to decide what school or program to attend. Therefore, it is critical that program websites be informative and regularly updated.

Many studies have evaluated the quality and comprehensiveness of program websites in different medical subspecialties [2-4]. All of the studies concluded that residency and fellowship websites have significant room for improvement despite their vital role in the decision-making process. According to our literature search, no study to date has 
evaluated the content of urogynecology fellowship websites. We believe that comprehensive program websites can increase interest of urogynecology fellowship applicants in a program. Therefore, the objective of this study was to evaluate the comprehensiveness of American and Canadian urogynecology fellowship websites and present recommendations to promote the subspecialty of urogynecology.

\section{Materials and methods}

The methodology for this study was developed from several recently published program website analysis studies [2-6]. Our study did not incorporate the use of human or animal subjects and used publicly available information on the internet. Therefore, Institutional Review Board approval was not required.

\section{Data collection}

A comprehensive list of American fellowship programs was obtained through The American Medical Association Fellowship and Residency Electronic Interactive Database (FRIEDA) [7]. For Canadian fellowship programs, a comprehensive list was compiled using the Society of Obstetricians and Gynecologists of Canada (SOGC) website [8] and a google search to ensure all fellowship programs in Canada were included. Fellowship programs that were published on a university website were also included in this study.

The website data from all American and Canadian fellowship programs were organized into a database. The data for this study were collected by one website reviewer (RV) and were recorded into a data collection Excel sheet. The data were checked by a senior reviewer (MJ).

\section{Website assessment}

To evaluate each fellowship program, a list of qualities desirable for a comprehensive fellowship program website was constructed and adapted from the scoring systems of several recently published studies [2-4]. The list comprised 72 attributes that were used to evaluate websites under 9 main categories: Recruitment, Current Fellows, Faculty Information, Research and Education, Surgical Program, Clinical Work, Benefits and Career Planning, Wellness, and Environment (Supplemental Table 1).

Information available on the website itself, hyperlinked on the website or contained in additional documents linked on the website was considered present and received a score on the criteria. Information not available on the website, hyperlinks, or additional documents but available elsewhere on the internet other than on the program's website was considered as not present. Percent score for criteria on program websites was calculated as a percentage of 'Yes' or 'Present' items divided by the total number of criteria.

The program websites were further grouped into geographical location by country [9]. American programs were grouped as per the following categories: Northeast, Midwest, West, and South (see Supplemental Table 2 for list of states included in each region). Canadian programs were grouped together in the geographical analysis.

\section{Statistical analysis}

Results are expressed as mean \pm SD unless otherwise stated. Statistical analysis was performed using SPSS Statistics version 26 (IBM Corporation). Programs were grouped by geographical location, and mean scores were compared with ANOVA with Bonferroni correction for multiple comparisons. Website scores were also compared between American and Canadian program websites using unpaired t-tests. $P<0.05$ was considered statistically significant.

\section{Results}

Using FRIEDA, 54 American urogynecology fellowship programs were identified. Of these programs, 98\% $(n=53 / 54)$ had available webpages listed on the FREIDA database, and 1 program website was obtained through a Google search. The SOGC database identified 11 urogynecology fellowship programs in Canada, and Google search identified 1 additional program. All American programs $(100 \%, n=54 / 54)$ and 91.7\% $(n=11 / 12)$ Canadian urogynecology programs had accessible websites.

\section{Geographical distribution}

Of the identified urogynecology programs, $81.82 \%(n=54 /$ 66) were American and $18.18 \%(n=12 / 66)$ Canadian. Of the American programs, $29.62 \%(n=16 / 54)$ were from the Midwest, $31.48 \%(n=17 / 54)$ from the Northeast, $24.07 \%$ $(n=13 / 54)$ from the South, and $14.81 \%(n=8 / 54)$ from the West (Table 1).

\section{American program websites}

After a comprehensive analysis of American program websites based on 72-item criteria, the mean score of the program websites was $46.46 \%(n=33.45 \pm 7.20$ out of 72$)$. Mean website scores for American programs varied by region. American program websites in the Northeast scored $43.625 \%$ ( $n=31.41 \pm 8.08$ out of 72$)$, in the West scored $43.93 \%$ ( $n=31.63 \pm 8.99$ out of 72$)$, in the Midwest scored $48.61 \%$ ( $n=35.00 \pm 8.14$ out of 72$)$, and in the South scored $47.652 \%(n=34.31 \pm 3.28$ out of 72$)$. 
Table 1 Mean score and programs per capita by geographical region

\begin{tabular}{|c|c|c|c|c|c|}
\hline & $\begin{array}{l}\text { Midwest USA } \\
(n=16)\end{array}$ & $\begin{array}{l}\text { Northeast USA } \\
(n=17)\end{array}$ & $\begin{array}{l}\text { South USA } \\
(n=13)\end{array}$ & $\begin{array}{l}\text { West USA } \\
(n=8)\end{array}$ & $\begin{array}{l}\text { Canada } \\
(n=12)\end{array}$ \\
\hline Overall criteria met & $35.00 \pm 8.14$ & $31.41 \pm 8.08$ & $34.31 \pm 3.28$ & $31.63 \pm 8.99$ & $19.73 \pm 3.77^{\#}$ \\
\hline$\%$ Overall criteria met & 49.8 & 43.6 & 47.6 & 43.9 & $27.5^{\#}$ \\
\hline
\end{tabular}

${ }^{\#} n=11$

The criteria that fellowship websites most included were electronic application service $(92.6 \%, n=50 / 54)$, educational background of faculty $(92.6 \%, \mathrm{n}=50 / 54)$, comprehensive faculty listing $(94.4 \%, n=51 / 54)$, and program description $(98.1 \%$, $n=53 / 54)$. The criteria with the lowest scores were messages from the department chair $(3.7 \%, n=2 / 54)$, research requirements to obtain admission $(1.9 \%, n=1 / 54)$, research presentations by the faculty $(1.9 \%, n=1 / 54)$, expected case load of fellows $(1.9 \%, \mathrm{n}=1 / 54)$, on-call responsibilities $(1.9 \%, \mathrm{n}=1 / 54)$, and career placement of program graduates $(1.9 \%, \mathrm{n}=1 / 54)$.

The mean scores also differed by subcategory $(p<0.001)$. The Wellness section had the highest prevalence of inclusion on websites $(64 \%, n=1.92 \pm 0.85$ out of 3 criteria) across all American program websites. Within this subcategory, the most reported criterion present on the website was mention of professional organizations related to the program $(92.6 \%$ $n=50 / 54)$. On the contrary, the Clinical Work section of the criteria had the lowest score $(15.17 \%, n=0.91 \pm 1.02$ out of 6 criteria) (Table 2). The least reported criteria in this subcategory were expected case load of fellows $(1.9 \%, n=1 / 54)$ and on-call responsibilities $(1.9 \%, \mathrm{n}=1 / 54)$.

\section{Canadian program websites}

After a comprehensive analysis of all 11 Canadian urogynecology fellowship websites based on the 72-item criteria, the mean score of the program websites was $27.40 \%$ ( $n=19.73 \pm 3.77$ out of 72). Within the 72-item criteria, the most found information on program websites was the contact email addresses for the programs $(100 \%, n=11 / 11)$ and the program description $(100 \%$, $n=11 / 11)$. The criteria with the lowest scores $(0 \%, n=0 / 11)$ were information on the interview process, research requirements to obtain admission, message from the program director, message from the department chair, research presentations by the faculty, past alumni names, alumni locations/where they work now, grants awarded to fellows, educational resources available to fellows, surgical statistics (i.e., number of cases performed per year), work hours, call schedule, on-call responsibilities, job incentives, moonlighting policy (i.e., ability to hold a second job), career placement of program graduates, associations with professional organizations, and house options.

Each subcategory of the criteria had varying mean scores $(p<0.001)$. For Canadian websites, the Faculty section had the highest score $(43.125 \%, 3.45 \pm 2.02)$. Within this subcategory the most found criterion was pictures of the urogynecology faculty displayed on the website $(72.7 \%, n=8 / 11)$. The lowest scoring section in respect to the criteria was the Clinical Work category at $(6 \%, n=0.36 \pm 0.67$ out of 6 criteria). The lowest scoring criteria within this subcategory were found to be work hours $(0 \%, n=0 / 11)$, call schedule $(0 \%, n=0 / 11)$, and on-call responsibilities $(0 \%, n=0 / 11)$.

\section{Comparing American and Canadian program websites}

American program websites scored significantly higher than Canadian websites (USA: $33.45 \pm 7.20$ out of 72 criteria;

Table 2 Mean number of criteria met on American and Canadian urogynecology fellowship program websites

\begin{tabular}{|c|c|c|c|c|c|}
\hline & \multicolumn{2}{|l|}{ USA } & \multicolumn{2}{|l|}{ Canada } & \multirow[t]{3}{*}{$P$ value } \\
\hline & \multicolumn{2}{|l|}{$(n=54)$} & \multicolumn{2}{|l|}{$(n=11)$} & \\
\hline & Mean \pm SD & $\%$ Completed & Mean \pm SD & $\%$ Completed & \\
\hline Recruitment & $9.58 \pm 2.13$ & 61.1 & $6.45 \pm 1.13$ & 43.1 & $<0.001$ \\
\hline Faculty information & $4.89 \pm 1.58$ & 46.0 & $3.45 \pm 2.02$ & 9.0 & 0.011 \\
\hline Current fellows & $2.30 \pm 1.68$ & 57.2 & $0.45 \pm 0.82$ & 32.7 & $<0.001$ \\
\hline Total research and education & $5.72 \pm 2.02$ & 27.7 & $3.27 \pm 1.42$ & 20.2 & $<0.001$ \\
\hline Total surgical program & $2.49 \pm 1.37$ & 15.2 & $1.82 \pm 1.25$ & 6.0 & 0.138 \\
\hline Total clinical work & $0.91 \pm 1.02$ & 49.8 & $0.36 \pm 0.67$ & 17.0 & 0.099 \\
\hline Total benefits and career planning & $3.98 \pm 1.98$ & 64.0 & $1.36 \pm 0.36$ & 39.3 & $<0.001$ \\
\hline Total wellness & $1.92 \pm 0.85$ & 28.3 & $1.18 \pm 0.87$ & 22.7 & 0.011 \\
\hline Total environment & $1.70 \pm 1.34$ & 46.5 & $1.36 \pm 1.03$ & 27.4 & 0.438 \\
\hline Overall criteria met & $33.45 \pm 7.20$ & 56.4 & $19.73 \pm 3.77$ & 37.9 & $<0.001$ \\
\hline
\end{tabular}

Note: Bolded $p$-values are significant 
Canada: $19.73 \pm 3.77$ out of 72 criteria; $p<0.001)$ in the following sections: Recruitment (USA: $9.58 \pm 2.13$ out of 17 criteria; Canada: $6.45 \pm 1.13$ out of 17 criteria; $p<0.001$ ), Current Fellows (USA $2.30 \pm 1.68$ out of 5 criteria; Canada $0.45 \pm 0.82$ out of 5 criteria; $p<0.001$ ), Research and Education (USA: $5.72 \pm 2.02$ out of 10 criteria; Canada 3.27 \pm 1.42 out of 10 criteria; $p<0.001$ ), and Benefits and Career Planning (USA: $3.98 \pm 1.98$ out of 8 criteria; Canada: $1.36 \pm$ 0.36 out of 8 criteria). There were no subcategories in the criteria for which Canadian program websites scored higher than American program websites.

\section{Discussion}

Our study highlights areas where American and Canadian urogynecology fellowship program websites have comprehensive information and areas where program websites can improve their content's completeness. We found that both American and Canadian program websites scored high in the Faculty Information section (Table 1). Our results are similar to another study by Stoeger and colleagues (2019) analyzing general surgery residency program websites. They found faculty information to be among the most commonly provided information on program websites, with $>85 \%$ of websites including the name and specialties of their faculty members [3]. Applicants have deemed faculty information to be useful in the program selection process as well as the satisfaction rate of a program, especially in respect to the search for a mentor or faculty advisor $[10,11]$.

Canadian websites obtained a mean score of $27.40 \%(n=$ $19.73 \pm 3.77$ out of 72 ) of items included. Compared to American Urogynecology program websites (mean score of $46.46 \%, n=33.45 \pm 7.20$ out of 72 ), there was a significant difference between countries, showing American program websites as more comprehensive. Moreover, American program websites did not receive a score of $0 \%$ in any of their criteria. Canadian websites received a $0 \%$ in $18 / 72$ criteria (Table 1).

Overall, both American and Canadian and urogynecology fellowship websites have room for improvement by adding regular updates to make them comprehensive. It is important to note that the Accreditation Council for Graduate Medical Education has accredited many American urogynecology programs. However, Canadian urogynecology programs are not recognized by the Royal College of Physicians and Surgeons of Canada $[12,13]$. As a result, Canadian programs may have a greater need to detail their programs on their websites.

Useful sections such as Benefits and Career Planning lacked mention in Canadian program websites with criteria such as incentives, moonlighting, and career placement of program graduates absent on all websites. A website analysis study assessing Pediatric Radiology Fellowship programs in Canada showed similar results of Canadian websites commonly omitting details regarding moonlighting and career placement of program graduates [14]. Few Canadian urogynecology program websites presented information on vacation opportunities, maternal leave, and paternal leave. These results differ from other Canadian fellowship program website analyses, where a study showed that across all Canadian radiology program websites, $63.7 \%$ provided vacation details [5]. This information is vital in a program website, as it identifies the aspect of work-life balance and conveys the program's commitment to a balanced life for their fellows.

In contrast, most American websites presented some information regarding Benefits and Career Planning with mention of vacation and incentives. However, we found that not many American program websites mentioned maternal leave $(46.3 \%, n=25 / 54)$ and paternal leave $(44.4 \%, n=24 / 54)$, despite a national parental leave policy available since 2016 . Over the years, there has been a significant change in the demographics of obstetrics and gynecology programs. In 2017, female physicians made up 36\% of the active physician workforce, $57 \%$ of practicing obstetrics-gynecology physicians, and $83 \%$ of residents [15]. As physicians who care for individuals through pregnancy and childbirth, training programs in obstetrics and gynecology should be pioneers in developing and implementing parental leave policies. With the increasing number of parents in medical training programs, urogynecology programs should consider the importance of including information about parental leave and vacation policies to ensure that current and future trainees have adequate access to such information.

Previous surveys and studies in various medical disciplines, such as internal medicine, diagnostic radiology, and maternal-fetal medicine, indicate that information such as career placement of program graduates, alumni information, and research opportunities are valuable to prospective applicants $[10,11,14]$. While research opportunities for fellows were mentioned on most websites, information on alumni and future career planning such as career placement of program graduates, future study opportunities, alumni names, and alumni locations were rarely present. Both American and Canadian urogynecology program websites should consider including information that applicants are interested in applying and choosing a program.

\section{Limitations}

There were some limitations to our study. First, the data were collected between May-June 2020 and did not account for any updates occurring after this time. Our study only looked at the comprehensiveness of websites. The quality or accessibility of website are important factors that can affect the utility of a program website, but these two factors were not evaluated 
in this study. The reviewer also had to sort through multiple attachments and links to access information on certain topics within the checklist. It is likely that some information may have been missed but this was minimized by review of the collected data by a second reviewer.

Although the criteria list provides a robust method to quantify and evaluate website content, they lend a degree of subjectivity to our data collection. We employed a training process prior to data collection to ensure the reviewer had a strong understanding of nuances of the criteria and navigating program websites and ensured reliability through a second check of the collected data. In addition, likely not all website content assessed by the criteria employed in this study were of equal importance to the applicant, which may have resulted in programs achieving a lower score. Future studies should conduct a detailed assessment of the content topics applicants find relevant.

Lastly, some aspects of a program may change frequently (such as call schedules or recent research presentations) and may be excluded on the website as a result. It may be more apt for content that is frequently changing to be discussed during the interview process rather than be posted on the program website due to risk of presenting outdated information online. Similarly, future studies should also assess the frequency at which program websites are updated and the accuracy of website content.

\section{Conclusion}

Urogynecology is a relatively new subspecialty of surgery; however, the increasing demand of urogynecology services indicates the need for fellowship-trained surgeons. The findings of this article highlight that overall, American, and Canadian urogynecology fellowship program websites include many content details relevant to applicants. Both American and Canadian program websites should increase the comprehensiveness of sections on Clinical Work and Benefits and Career Planning to assist applicants. Program websites are one of the main points of contact between urogynecology programs and potential candidates, especially during the current COVID-19 pandemic and resulting national/global travel restrictions. Through a comprehensive website, programs can reach a wide audience and attract the most qualified candidates.

Supplementary Information The online version contains supplementary material available at https://doi.org/10.1007/s00192-021-04808-9.

Contributors MJ designed the study, participated in data collection and manuscript preparation. NS performed the analysis and assisted with manuscript preparation. RV participated in data collection and manuscript preparation. DLK participated in study design and manuscript preparation. ABA reviewed and provided input on the manuscript. FK participated in study design and manuscript preparation. All authors have approved the final version of the manuscript.

\section{Declarations}

IRB/ethics committee statement Our study did not incorporate the use of human or animal subjects and used publicly available information on the internet, and therefore the approval of the Institutional Review Board was not required.

Conflicts of interest None.

\section{References}

1. Sharma R, Verma U, Sawhney V, Arora S, Kapoor V. Trend of internet use among medical students. JK Sci J Med Educ Res. 2006;8:101-2.

2. Charalel RA, Pua BB, Galla N, Trehan SK, Madoff DC. Interventional radiology fellowship website content: what is the relevance to potential applicants? Clin Imaging. 2016;40(6): 1070-4. https://doi.org/10.1016/j.clinimag.2016.06.011.

3. Stoeger SM, Freeman H, Bitter B, Helmer SD, Reyes J, Vincent $\mathrm{KB}$. Evaluation of general surgery residency program websites. Am J Surg. 2019;217(4):794-9. https://doi.org/10.1016/j.amjsurg. 2018.12.060.

4. Khan MS, Hayat J, Marsia S, et al. How well do we represent ourselves: an analysis of cardiology fellowships website content. Futur Cardiol. 2020;16(4):281-7. https://doi.org/10.2217/fca2019-0015.

5. Sugrue G, Hamid S, Vijayasarathi A, Niu B, Nicolaou S, Khosa F. An evaluation of the content of Canadian radiology fellowship websites. Curr Probl Diagn Radiol. 2020;49(4):243-7. https://doi. org/10.1067/j.cpradiol.2019.06.004.

6. Adham S, Nasir MU, Niu B, Hamid S, Xu A, Khosa F. How well do we represent ourselves: an analysis of musculoskeletal radiology fellowships website content in Canada and the USA. Skeletal Radiol. Published online June 16, 2020. https://doi.org/10.1007/ s00256-020-03481-1.

7. FREIDA Residency Program Database | Medical Fellowship Database | AMA. Accessed August 18, 2020. https://freida.amaassn.org/

8. Residents. Accessed August 18, 2020. https://www.sogc.org/en/ content/events/residents.aspx

9. Gibney B, Redmond CE, Niu B, et al. A comparative evaluation of cardiothoracic radiology fellowship website content. J Thorac Imaging. 2020;35(3):W82-6. https://doi.org/10.1097/RTI. 0000000000000477.

10. Caiola E, Litaker D. Factors influencing the selection of general internal medicine fellowship programs. J Gen Intern Med. 2000;15(9):656-8. https://doi.org/10.1046/j.1525-1497.2000. 06389.x.

11. Sciscione AC, Colmorgen GH, D'Alton ME. Factors affecting fellowship satisfaction, thesis completion, and career direction among maternal-fetal medicine fellows. Obstet Gynecol. 1998;91(6):1023-6. https://doi.org/10.1016/s00297844(98)00076-3.

12. The Royal College of Physicians and Surgeons of Canada: Information By Discipline. Accessed September 14, 2020. http:// www.royalcollege.ca/rcsite/ibd-search-e

13. Fellowship Programs - Education | AUGS. Accessed August 18, 2020. https://www.augs.org/education/fellowshipprograms/ 
14. Lu F, Vijayasarathi A, Murray N, Hamid S, Khosa F. Evaluation of pediatric radiology fellowship website content in USA and Canada. Curr Probl Diagn Radiol. Published online January 11, 2020. https://doi.org/10.1067/j.cpradiol.2020.01.007.

15. 2018 Physician Specialty Data Report Executive Summary. AAMC. Accessed August 18, 2020. https://www.aamc.org/data- reports/workforce/data/2018-physician-specialty-data-reportexecutive-summary

Publisher's note Springer Nature remains neutral with regard to jurisdictional claims in published maps and institutional affiliations. 